\title{
The influence of shared R\&D-project innovativeness perceptions on university-industry collaboration performance
}

\author{
Carsten Schultz ${ }^{1}$ - Oliver Gretsch ${ }^{2}$ (D) $\cdot$ Alexander Kock ${ }^{2}$ (D)
}

Published online: 3 August 2020

(C) The Author(s) 2020

\begin{abstract}
University-industry collaboration (UIC) partners' different organizational backgrounds entail socialization with distinct thought worlds, management approaches, and therefore diverging goals, which may lead to differences in their perceptions of the R\&D challenge. These differences can hamper relationship quality and may cause coordination challenges. Using dyadic survey data of 164 UIC project managers of 82 projects, we analyze the consequences of partners' shared R\&D-project innovativeness perceptions for project performance. We consider the planning intensity and the collaboration in the planning process as antecedents to partners' shared perceptions. We find that partners' shared R\&D-project innovativeness perceptions increase project performance. We also show that collaborative planning enhances shared perception. Moreover, we find support that planning intensity (i.e., formal control) and collaborative planning (i.e., social control) complement each other. Hence, if both partners are involved in a collaborative and intensive planning process, they will more likely exhibit a shared R\&D project innovativeness perception and, therefore, increase UIC project performance. This will help to manage their R\&D activities to create a sense of ownership and to prevent inefficient project deviations.
\end{abstract}

Keywords University-industry collaboration · Project planning · Project control $\cdot$ Shared R\&D project innovativeness perception · Thought worlds $\cdot$ Multi-informant survey study

JEL Classification $\mathrm{M} 10 \cdot \mathrm{O} 32 \cdot \mathrm{O} 36$

Carsten Schultz

schultz@bwl.uni-kiel.de

Oliver Gretsch

gretsch@tim.tu-darmstadt.de

Alexander Kock

kock@tim.tu-darmstadt.de

1 Institute for Innovation Research, Kiel University, Christian-Albrechts-Universität zu Kiel, Westring 425, 24118 Kiel, Germany

2 Chair for Technology and Innovation Management, Technische Universität Darmstadt, Hochschulstr. 1, 64289 Darmstadt, Germany 


\section{Introduction}

University-industry collaboration (UIC) is of central importance in open research and development (R\&D) processes (Bozeman et al. 2013; Perkmann and Walsh 2007). Universities supply firms with state-of-the-art technological and market-related knowledge (Sherwood and Covin 2008; Wirsich et al. 2016), which can lead to substantial innovation (Baba et al. 2009; Spanos et al. 2015). Moreover, universities provide access to well-equipped laboratories and highly qualified staff (Bishop et al. 2011; Feller et al. 2002; Hagedoorn et al. 2000; Mora-Valentin et al. 2004). Firms' demand for highly specialized expertise and enhanced technological knowledge from a variety of external sources (Belderbos et al. 2014; de Rassenfosse et al. 2016), drives UIC's growing importance (Qiu et al. 2017).

However, the collaboration process often faces challenges such as the differences in the objectives, structures, processes, and cultures of the partners, as well as their different interpretations of the UIC project's R\&D challenge to solve (Bercovitz and Feldman 2007; Boardman and Ponomariov 2009; Plewa and Quester 2007). Academics generally strive to establish their scientific reputation through publications, often preferring outcomes with a long-term impact (Perkmann et al. 2013; Salter et al. 2017). Collaboration with firms provides universities with new funding opportunities, but also allows the commercialization of their research results (D'Este and Perkmann 2011; Rothaermel et al. 2007). However, this may come at the cost of threats to their academic freedom (Tartari and Breschi 2012). In comparison, firms focus more on generating market value and short-term benefits (Bercovitz and Feldman 2007). Hence, such fundamental differences may hamper the effectiveness of interorganizational interactions (Gerwin 2004).

The literature has often highlighted the relevance of relational barriers in UIC, although their impact on UIC project performance has not been investigated. Furthermore, although facets of governance and control have been addressed (Bstieler et al. 2015; Gesing et al. 2015), a more profound understanding is required of the micro foundations of collaborative challenges on a project level. For instance, finding the appropriate balance of firm managers' need for project formalization and university researchers' requirements for autonomy remains an important issue to resolve (Du et al. 2014). Similarly, given partners' highly diverse backgrounds, the effects and the interplay of formal and social controls on UIC project's management need a more profound understanding (Rijsdijk and van den Ende 2011).

We propose that a UIC project's performance depends on the partners' shared perceptions of the R\&D project innovativeness. First, we base this assumption on the concept of 'thought worlds' by Dougherty (2008) and on Heider's balance theory (Heider 1965), both of which provide a sound theoretical basis for understanding the effects of inter-functional actors' perceptions of R\&D projects. 'Thought worlds' describe the perceptions that individuals share with respect to a social environment. In essence, individuals create perceptions and beliefs depending on their experiences and interactions with their environment (Nooteboom et al. 2007). Balance theory suggests that two actors will strive to maintain a sense of balance to ensure a positive relationship quality while simultaneously being consistent in their own thought worlds (Heider 1965). Second, and closely related to the concepts of thought worlds and balance theory, we build the assumptions mentioned above on the concept of 'cognitive distance'. In general, cognitive distance means that collaboration partners are characterized by heterogeneous backgrounds which influence how they interact with their environment (Nooteboom et al. 2007). Thus, collaboration partners' diverse knowledge input is supposed to enhance 
innovative outcomes, but concurrently, may limit partners' capabilities to successfully transfer the project results (Filiou and Massini 2018; Muscio and Pozzali 2013). Put differently, we propose that despite UIC partners' cognitive distance being conducive for potentially innovative outcomes, their shared $R \& D$ project innovativeness perceptions may be relevant for UIC project performance.

The first research question that we address is therefore: What influence do partners' shared $R \& D$ project innovativeness perceptions have on UIC project performance? Following organizational control theory, partners' joint planning as a formal control could increase their shared perception (Ouchi 1979), and social controls could enable the distribution of information and knowledge to the project members (Rijsdijk and van den Ende 2011). Building on these insights, we address the second research question: What impact do formal and social controls have on partners' shared $R \& D$ project innovativeness perceptions?

Previous studies provide rich insight into the management competences needed for successful, collaborative R\&D projects (Gesing et al. 2015; Hagedoorn et al. 2000; Schleimer and Faems 2016). Congruence in partners' knowledge bases facilitates communication and collaborative interactions (Sherwood and Covin 2008), but more distant knowledge is often required to enhance innovation performance (Filiou and Massini 2018; George et al. 2008; Nooteboom et al. 2007). Balancing these partly contradictory needs of firms may pose challenges when interacting with universities (Bercovitz and Feldman 2007; Sampson 2007). Moreover, the cognitive distance between collaborating firms and universities (i.e., their different mindset and organizational background) is likely to lead to variances in their approaches to collaboration management (Muscio and Pozzali 2013; Perkmann and Walsh 2007) and may bear an increased risk of failure (Guzzini and Iacobucci 2017; Jain et al. 2009; Lhuillery and Pfister 2009). Relational peculiarities rooted in different cultures have been analyzed from various perspectives, including supportive management activities, product or process innovation's determinants, and the commercialization of collaborative results (Maietta 2015; Mora-Valentin et al. 2004; Perkmann et al. 2013).

Closely linked to the divergent organizational cultures and cognitive distance of collaboration partners in UIC, technology transfer offices (TTOs) have been analyzed in their brokering role for establishing and managing university-industry relationships (Gubitta et al. 2016; Lafuente and Berbegal-Mirabent 2019; Muscio 2010). As an intermediary, a university TTO connects the explorative part, i.e. university scientists, with the exploitative commercialization part, i.e. firms' managers, therefore reducing uncertainty and barriers related to asymmetric information, and legitimizing commercialization activities (Siegel et al. 2007). Hence, TTOs facilitate the transfer of university scientists' research findings into public and entrepreneurial practice, the commercialization of university researchers' intellectual property, and provide a valuable pool of highly qualified young professionals for industrial job markets (Fitzgerald and Cunningham 2016; Muscio 2010).

Beyond this, scholars have indicated that firms need to manage UIC projects differently than they manage firm-internal or interfirm R\&D projects (Belderbos et al. 2014; Bstieler et al. 2015; Cassiman et al. 2010; Du et al. 2014). According to recent studies, the formalization level, i.e. projects' governance, is a critical issue in UIC, which should be adapted to the partner and the type and maturity of the project in order to enhance its performance (Cassiman et al. 2010; Du et al. 2014). UIC projects are more explorative by nature and university researchers require a certain level of academic freedom and flexibility for working effectively (Gama et al. 2017). Furthermore, basic research projects may require a different steering compared to contract research projects which aim for incremental improvements. 
This study contributes in two ways to the existing bodies of literature on UIC and control theory. First, we introduce partners' shared R\&D project innovativeness perception as a construct to provide a more in-depth insight into UIC partners' cognitive distance and how this affects partners' relationship. Although previous UIC research has described relational barriers in such projects, no study has investigated why and how a shared perception of the R\&D project delivers value to the partners and contributes to project performance. Second, we contribute to the literature on control theory by analyzing the joint effects of formal and social controls on partners' shared perceptions and their effects on UIC project performance. Using this approach, we build on research in the field of open innovation and contribute to our understanding of specific control modes' impact on performance in the context of the collaboration of cognitively distant partners, such as firms and universities.

\section{Theoretical background}

\subsection{Shared R\&D project innovativeness perception}

Scholars have supposed that differences between collaborating firms' perceptions remain stable over time (Nooteboom et al. 2007), and that their managers are likely to perceive stimuli and challenges inherent to the project differently (Spender 1996). These effects may originate from different organizational backgrounds, since organizational members have undergone cognitive changes during their socialization (Michel 2007). Professionals therefore adapt their cognitive processes to their industrial context (Filiou and Massini 2018). These professionals' dispositions, socialization, knowledge, competencies, and mental models regarding reality are likely to affect their assessment of collaborative R\&D projects (Dougherty 2008). Comparably to firm managers' socialization, university researchers also adapt their cognitive processes to their academic work environment, which will in turn influence their perception of R\&D projects and may lead to an increased cognitive distance in UIC (Filiou and Massini 2018; Muscio and Pozzali 2013; Sampson 2007).

UIC partners differ vastly regarding their skill sets, orientations, working styles, mental processes, and attitudes; consequently, they are likely to exhibit these discrepancies (Nooteboom et al. 2007; Okamuro and Nishimura 2013). Firms generally prefer immediate solutions to existing problems and are often concerned about secrecy and intellectual property (Belderbos et al. 2014; Bercovitz and Feldman 2007). Conversely, rather long-term scientific research and more open and informal academic cultures are characteristic for universities (Jain et al. 2009; Schartinger et al. 2002). In the academic system, a detailed analysis of research issues, a more open discourse on research findings, and collaboration with multiple partners are essential for impact and performance (Okamuro and Nishimura 2013; Salter et al. 2017).

Bstieler et al. (2017) provide several angles to approach and assess UIC partners' potential differences. Building on dyadic UIC data, they emphasize the relevance of partners' demographic similarity related to their educational background, the importance of reciprocal communication, and decision process similarity so that partners can share a common understanding and approximate in their ways of decision-making to develop mutual trust. Although these are certainly relevant influences on shared R\&D project perceptions, we focus in our study on the UIC projects' core characteristics: UIC projects cover multiple types of R\&D challenges that differ regarding their technological content and their degree of innovativeness, for example, from basic research to more applied R\&D projects 
(Bstieler et al. 2015). The degree of innovativeness is a core project characteristic defining, for instance, project goals, work approaches, the type of knowledge involved (i.e., tacit or explicit), time horizons, and project outcomes (Kobarg et al. 2018; Santoro and Bierly 2006; Schultz et al. 2013b). Innovation is often the core objective of UIC projects to generate new knowledge and technological progress, which may eventually result in patents and new products (Bstieler et al. 2015; Wirsich et al. 2016). Accordingly, we use the UIC project's degree of innovativeness (i.e., the overarching innovation goal) to represent the nature of a particular project's $R \& D$ challenge to solve and therefore as the basis for partners' R\&D project perceptions.

Innovativeness describes the intensity of technological, resource-related, and marketrelated changes that allow the assessment of a project's potential benefits and risks (Szymanski et al. 2007). Most scholars conceptualize innovativeness as a continuous construct ranging from incremental to radical, and comprising several dimensions relating to market and technology changes (Kock et al. 2011; Schultz et al. 2013b; Talke et al. 2010). For instance, technological innovativeness relates to changes in new products' technological components, and highly innovative technologies often force a firm to alter its knowledge base (Kock et al. 2011). The market dimension of innovativeness relates to the changes that new products cause in a market. A radical innovation exhibits both high technological innovativeness and high market innovativeness (Chandy and Tellis 1998). Hence, radical innovation involves high levels of uncertainty and therefore requires experimentation and a certain risk-taking propensity (Kock et al. 2011).

Both partners need to combine their inputs for successful (radical) innovation to occur (Bstieler and Hemmert 2010; Santoro and Bierly 2006). Diverse partners' inputs and interplay are crucial for successful innovation, but their different functional backgrounds may seriously challenge their interactions' effectiveness (Bengtsson et al. 2015; Bstieler and Hemmert 2015). People exhibit structural differences due to their prior experiences (Balogun and Johnson 2004; Rousseau 2001), interests, and objectives (Vlaar et al. 2006). Various concepts such as department-specific thought worlds and orientations (Dougherty 1992), diverse mental models in teams (Lim and Klein 2006), competing values within organizations (Buenger et al. 1996), and functional diversity (Cannella et al. 2008) suggest that individuals with different functional backgrounds could exhibit great differences in their perceptions of reality (Maitlis 2005). In this vein, Schultz et al. (2013b) found that marketing and technology professionals differ in their perception of an R\&D project and their assessment of the project's degree of innovativeness. Following these insights, we assume that the potential differences in universities' and firms' interpretation of an R\&D project's degree of innovativeness may also reflect their differences in perception due to their organizational backgrounds.

\subsection{Performance effects of shared perceptions}

Balance theory (Heider 1965) substantiates the proposition that a shared perception of an R\&D project is relevant, because both collaboration partners will likely strive for cognitive consistency. It links the shared perception of two actors to their relationship quality. Balance theory suggests that individuals strive to maintain a sense of balance while being consistent in their own cognition. Thus, collaboration partners attempt to reach " $a$ harmonious state, one in which the entities comprising the situation and the feelings about them fit together without stress" (Heider 1965, p. 180). Following Heider (1965), two different actors' social systems, i.e. their coherent structures and backgrounds that make them 
belong to their respective group, always strive to achieve balance in their relations and in the shared objective relevant to both. Figure 1 illustrates the four different outcomes that may emerge when this social system achieves balance.

Two levels of relationship quality may emerge. First, firms and universities may attain a positive relationship characterized by mutual trust, commitment, and a generally strong willingness to collaborate (Bstieler et al. 2017; Hoegl and Gemünden 2001). This relationship achieves balance, because the two actors share the perception of the R\&D project's degree of innovativeness: either both perceive a high (type I) or both perceive a low (type III) level of innovativeness. Second, industry and university may display a negative relationship (type II and IV). This negative relationship arises as both partners have diverging perceptions of the common decision object, which leads to an unbalanced system. In this instance, the partners do not share a common $R \& D$ project perception. Consequently, one partner must believe that the $R \& D$ project is more innovative than the other one does.

UIC partners' divergent perceptions of R\&D project innovativeness which are often imposed by their different organizational backgrounds and purposes they aim to pursue may also be challenging for a collaboration. Muscio and Pozzali (2013, p. 489) highlight the ambiguity of partners cognitive distance: on the one hand, this distance is considered advantageous for more distal knowledge integration and innovative outcomes, on the other hand, cognitive distance may become impeding for partners' interaction and knowledge transfer as they may struggle to communicate and work efficiently. Hence, if partners' cognitive distance becomes too great, it may limit firm managers' absorptive capacities and learning capabilities, because the collaboration may become very complex and intensive to coordinate (Filiou and Massini 2018; Nooteboom et al. 2007). Cognitively distant collaboration partners will likely continuously strive to align their cognitive perceptions which could make them prone to cherry-picking when assessing information or interpreting content (i.e., content supportive to the own notion is valued higher than other contents) (Weeth et al. 2020).

If a university and a firm share the same perception of the R\&D project innovativeness, they will probably have a positive relationship that allows them to align their contributions based on their shared goals. Hence, partners will clearly understand the relevant

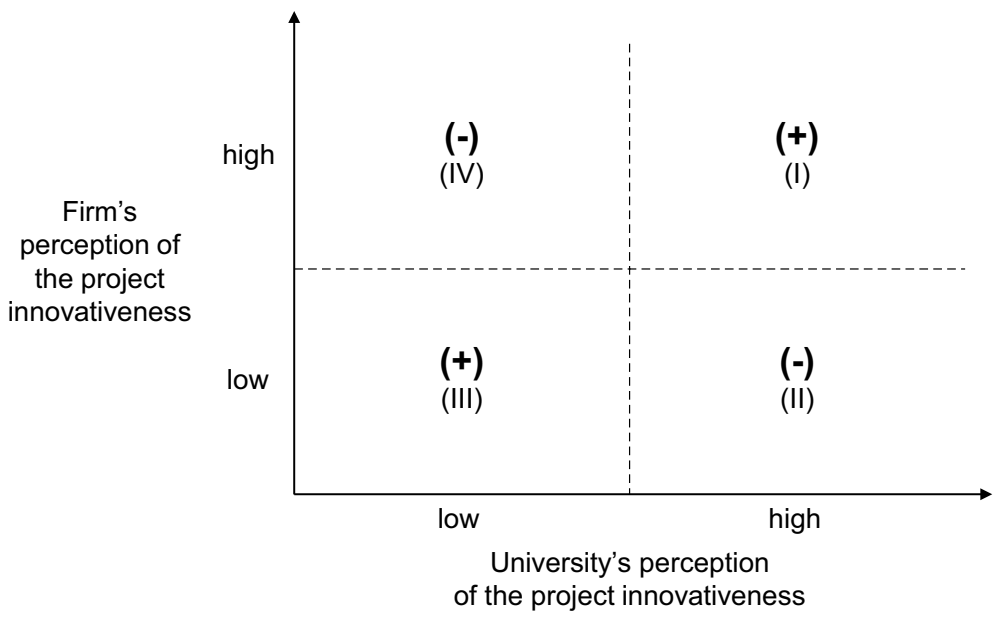

Fig. 1 High and low relationship quality between firms and universities in balanced social systems 
specification criteria and can determine the technological choices that will be most promising (Filiou and Massini 2018). This positive relationship may encourage partners to manage their R\&D activities more systematically (Shaner et al. 2016), because shared goals ensure that all of the parties understand what they are trying to achieve and how this path should be pursued (Bstieler et al. 2015; Hoegl and Parboteeah 2006). This shared perception creates a sense of ownership and support, while limiting the number of inefficient deviations from the project goals (Salomo et al. 2007). Thus, shared perception helps partners to concentrate their resources on defined areas and facilitates their coordination of cross-functional inputs, which are essential for successful projects (Tessarolo 2007; Turner and Makhija 2006).

\section{Hypotheses}

\subsection{Partners' shared R\&D project perceptions and project performance}

A shared perception of an $\mathrm{R} \& \mathrm{D}$ project facilitates efficiency in managing the project as partners can focus on project-related challenges instead of on using their resources to deal with their different perceptions (Shaner et al. 2016) and with the potential relational conflicts associated with these (Dougherty 1992). Mutual understanding will help smooth the collaboration and prevent the relationship from degenerating into distrust and distress (Bstieler et al. 2015) as partners will show a higher level of tolerance of failures and mistakes. This is especially crucial in the context of highly uncertain research outcomes as it is the case in UIC projects (Guzzini and Iacobucci 2017; Lhuillery and Pfister 2009). Furthermore, the team members' social identification with the group will increase (Sethi et al. 2001). A shared perception of challenges inherent to the R\&D purpose will help partners overcome internal and external barriers arising from the interaction and it will improve UIC project performance (Lazzarotti et al. 2016). Partners' shared R\&D project innovativeness perception contributes to ensuring that firms can better understand, transfer, and integrate the collaboration results (i.e., better ensure UICs major goals), while universities can combine firms' contributions with their own research findings (Zahra and George 2002). Beyond that, partners' shared perception can facilitate communication and enhance trust (Mora-Valentin et al. 2004). Trust in the collaboration partner and the explicit articulation of relevant knowledge are key drivers of UIC success (Bishop et al. 2011; Santoro and Bierly 2006). Moreover, trust in and commitment to R\&D collaboration will enhance UIC project results' (e.g., new technology, new intellectual property) compatibility with firms' product portfolios and facilitate knowledge and technology transfer (Bruneel et al. 2010; Bstieler et al. 2015). Hence, we hypothesize:

H1: In UIC projects, partners' shared R\&D project innovativeness perception is positively related to project performance.

\subsection{Organizational control theory}

Organizational control theory provides a theoretical explanation and practical guidance how different control mechanisms will support to achieve desired goals depending on task/project characteristics (Ouchi 1979). Control theory distinguishes between formal 
and informal control mechanisms which have, depending on the surrounding conditions, different implications on performance (Rijsdijk and van den Ende 2011).

Formal control mechanisms are differentiated into outcome control and process (i.e., 'behavior') control (Eisenhardt 1985; Johnson 2011; Ouchi 1979; Rijsdijk and van den Ende 2011). Both mechanisms align individual behaviors with organizational goals (i.e., project goals). Outcome control refers to specifying desired outputs but leaves the responsibility for realizing the output to the actors on the operating level (Rijsdijk and van den Ende 2011). Outcome controls may comprise the measurement of key performance indicators or (financial) rewards provided to project members (Turner and Makhija 2006). Process controls define the appropriate behaviors of those who get the tasks done and specify the processes they should adhere to (Turner and Makhija 2006). This may include hierarchies, rules, regulations and procedures project members have to follow.

Informal control mechanisms are effectively summarized in clan control, which help develop shared norms and values (Ouchi 1979). Clan control can be understood as an informal socialization process among individuals to align their beliefs and understanding to generate shared ones (Turner and Makhija 2006). Clan control may be realized in frequent communications and project members' interactions (Rijsdijk and van den Ende 2011).

\subsection{Effect of up-front planning on partners' shared R\&D project perceptions}

As a formal project management technique which combines both types of formal controls, up-front planning defines the objectives of $R \& D$ projects and the required steps to achieve them (Rijsdijk and van den Ende 2011) and may therefore help create a shared perception of the R\&D project's innovativeness. Before a project starts, actors undertake planning and preparation activities, which may incorporate feasibility studies, problem and project structuring activities, and goal clarification (Mora-Valentin et al. 2004). Up-front planning includes outcome controls as deliverables that project teams have to prepare and defines the various criteria that the project has to ultimately meet. Consequently, collaboration partners' interactive planning up-front will presumably be a promising means to support project execution in a more structured manner, but also contribute to project performance. For instance, process controls subdivide the project and require the team members to perform specific responsibilities (Kleinschmidt et al. 2007). Partners' joint planning will positively influence their shared $R \& D$ project innovativeness perceptions and, therefore, directly and positively affect project performance. However, over-excessive planning is expected to result in bureaucratic structures which may limit the flexibility and freedom needed for academic research (Rijsdijk and van den Ende 2011). Transparent plans comprising concrete goals, actions, and responsibilities, will assist collaboration partners to perform best (Gama et al. 2017). Formal controls, such as planning, help distribute information and knowledge across the team members (Schultz et al. 2013a). Applying formal controls helps the project leaders to clarify the project goals, actions, and required results (Salomo et al. 2007). Upfront planning codifies specific terms and communication channels, which the partners use in an identical manner. Formal planning processes may therefore generate a shared perception of the R\&D project (Rijsdijk and van den Ende 2011; Turner and Makhija 2006).

$\mathrm{H} 2$ : In UIC projects, the intensity of up-front planning is positively related to partners' shared R\&D project innovativeness perceptions. 


\subsection{Collaboration in the planning process}

Organizational control theory also includes social controls that rely on a socialization process to eliminate goal incongruence within organizations (Johnson 2011; Turner and Makhija 2006). The university is usually responsible for establishing a detailed plan and may also provide the majority of the team members. The firm could exercise social control, for example, by becoming actively involved in the project planning and management processes (Gesing et al. 2015). In this situation, both partners will be actively involved in defining the exchange processes and in developing personal ties so that the relationship's effectiveness will be enhanced (Bozeman et al. 2013; Walter et al. 2015). These actions will help provide the project members with a sense of common ground and shared goals (Albats et al. 2018; Kirsch 1996; Plewa and Quester 2007).

Firms' active participation in the planning process could have mixed effects. On the one hand, managers may change the project goals and influence critical decisions. Because the firm can be considered a sponsor in the relationship, it may have or require more influence on decision-making processes (Bercovitz and Feldman 2007; Lacetera 2009). Consequently, universities might regard firms' involvement as an unwanted interference to academic freedom and autonomy in innovative endeavors (Tartari and Breschi 2012). Overly intense firm involvement could reduce university researchers' commitment to the project and, therefore, exacerbate the potential differences in the partners' R\&D project perceptions. On the other hand, firm sponsors' support could also have a positive influence on UIC, because it could help motivate individuals and teams to work hard and according to common goals (Yadav et al. 2007). Social control also engenders greater flexibility and solidarity, more intensive information exchange, informal communication channels, and joint decision-making processes (Johnson 2011; Turner and Makhija 2006). These effects stimulate stronger interaction between the partners and enhance their shared perception of the R\&D projects, as well as of their common values (Das and Teng 2001; Lawson et al. 2009). UIC projects comprise more tacit knowledge and entail a higher level of ambiguity that both require rich communication and joint sense-making ( $\mathrm{Li}$ et al. 2010). If both partners' project leaders are personally involved in project planning processes, firms are more likely to accept universities' specific needs and goals (Albats et al. 2018). This approach also builds and enhances partners' trust and commitment (Bstieler et al. 2015). With regard to collaborative planning's impact on the learning outcomes of interorganizational development teams, Bstieler and Hemmert (2010) show that a collaborative approach to problem solving is the most important driver of success. Accordingly, we hypothesize:

H3: Collaborative planning is positively related to partners' shared R\&D project innovativeness perceptions.

\subsection{Planning intensity and collaborative planning as complements}

Li et al. (2010) suggest that formal control (i.e., planning intensity) and informal, social control (i.e., collaborative planning) complement each other, because social controls may remedy formal controls' limitations and because the two controls reinforce each other. Project planning is essential for aligning both partners' innovativeness perceptions and for coordinating their activities (Gama et al. 2017). Their interaction in the planning process helps ensure that the team members comply with the plans and adhere to the project goals (Plewa and Quester 2007). Knowing that the partner is involved in the project planning process can enhance the plan's relevance and transparency. Social control ensures 
that both partners exchange information during the planning process and that everybody obtains more project-specific information (Bstieler and Hemmert 2015). Team members can make better joint decisions on the basis of increased transparency (Kelley and Lee 2010). The involvement of both partners enhances the up-front planning process's efficacy by reducing the ex-ante criteria's inflexibility of single-sided planning activities (Morandi 2013). Stronger interactions may induce firm managers to rely less on rules and to relax their objectives by adapting to the unanticipated variations that may occur during the project (Sethi and Iqbal 2008). UIC projects have to cope with a high level of uncertainty, which means that variations are ubiquitous. If the firm partner is not actively involved in the project planning process, the official ex-ante project plan will differ from the actual project content later in the $\mathrm{R} \& \mathrm{D}$ process. We assume that the degree of firm involvement affects the up-front planning process in UIC projects by enriching the communication channels, ensuring better compliance, and through its greater flexibility. Accordingly, we hypothesize:

H4: Collaborative planning and planning intensity are complementary, because the positive relationship between planning intensity and shared $R \& D$ project perception is stronger when planning is done collaboratively and weaker when it is done individually.

Figure 2 summarizes this study's research framework. It shows the supposed direct effects between variables displayed by arrows and indicates the assumed interaction effect of collaborative planning on the relationship between planning intensity and shared project perceptions.

\section{Method}

\subsection{Data and sample}

We use the UIC project as the level of analysis to investigate how collaborative planning and planning intensity are related to the entities' shared R\&D project perception and

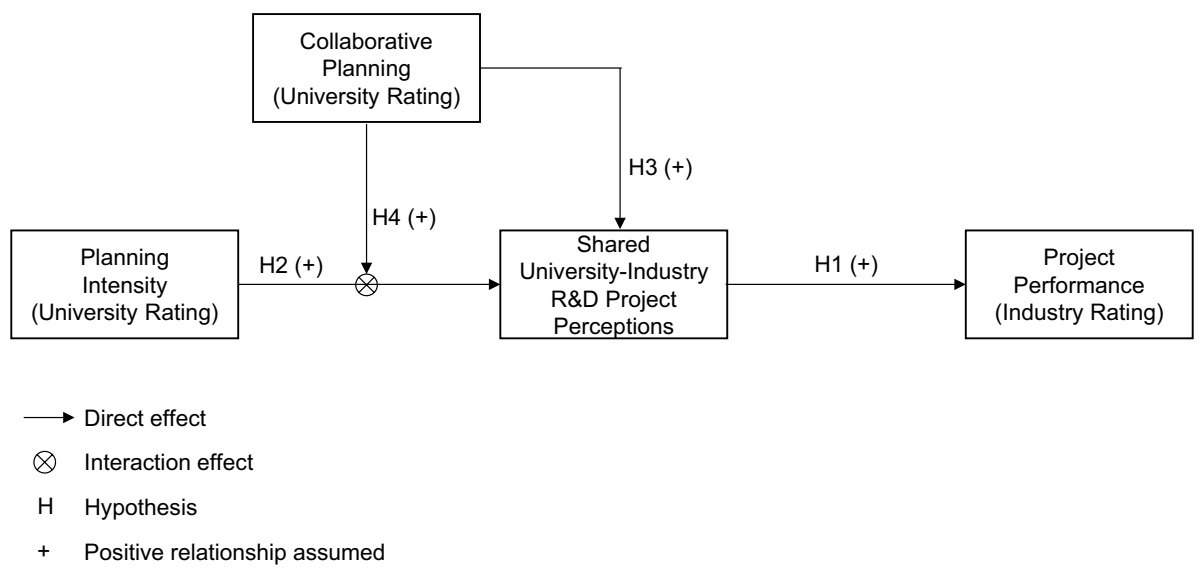

Fig. 2 Research framework 
eventual performance. Influences related to the organizational levels, such as a firm's general research intensity and its willingness to engage in open innovation, also influence the planning and the outcomes of UIC projects. We test the proposed model by using a sample of UIC projects that a single large multinational technology firm performed and completed. Limiting the data collection to a single firm allowed us to analyze the study context under comparable organizational and structural influences. The company is globally active, has a long tradition in innovation and an R\&D intensity of approximately 6 percent. The firm conducts R\&D projects with selected universities worldwide. All projects are related to joint technology development in industries such as energy, electronics, information and communication technology, infrastructure, and medical engineering. We only include projects that the firm co-financed to ensure that the collaboration is economically relevant. Payments made to universities were used to cover various costs, including the researchers' salaries, materials, and travel costs. We do not assess publicly financed projects in which the firm acted as a partner in a consortium without providing additional financial support. In all cases, the firm acted as a sponsor for university researchers (i.e., contract research) or provided at least part of the resources for the collaboration. We only target UIC projects that were completed not earlier than 2 years prior to this study. Table 1 comprises additional information concerning UIC projects' characteristics.

We identified potential projects by means of the firm's internal database. The firm and university project leaders were contacted and asked to participate in this study after we explained the objectives, procedures, and individual benefits that it could have for the participants. We subsequently contacted those project leaders who showed interest in the study by phone and conducted a 2 -h structured interview using a standardized questionnaire. This procedure ensured that the respondents had a similar understanding of all of the questions. Overall, we identified 142 projects. The firm's institutional support induced a sufficient response rate of $72 \%$ (i.e., 103 projects). In addition, we only used cases with complete information from both sides for this study. By including dyadic project assessments, we decreased the potential common method bias and therefore accounted for a distortion prevalent in certain previous studies in the field. The final sample comprised 164 respondents from 82 projects. We did not find significant differences between the used and unused cases with regard to performance ratings.

\subsection{Measures}

To measure project performance, the firm project leaders assessed the UIC project's impact on its profitability, revenues, market share, and competitive advantage. These criteria follow the core metrics used by Griffin and Page (1993) and more recent studies (Schultz et al. 2013b) to measure the financial and product dimensions of new product performance. Although new product performance is not equivalent to UIC project performance, we draw attention to an important connection. UIC projects covering pre-competitive early-stage research have an essential impact on the type of new product development, on its innovativeness for the firm, and on its potential regarding later market success (Florén and Frishammar 2012; Verworn 2009). Furthermore, this performance measure may come closer to what constitutes 'success' from the firm's perspective if compared to other previously used measures such as the overall satisfaction or fulfillment of expectations in the UIC project (Mora-Valentin et al. 2004; Perkmann et al. 2011). We asked the firm project leaders to provide information about these measures based on a seven-point Likert scale. The appendix lists all the items for this measure and the ones mentioned in the following. 


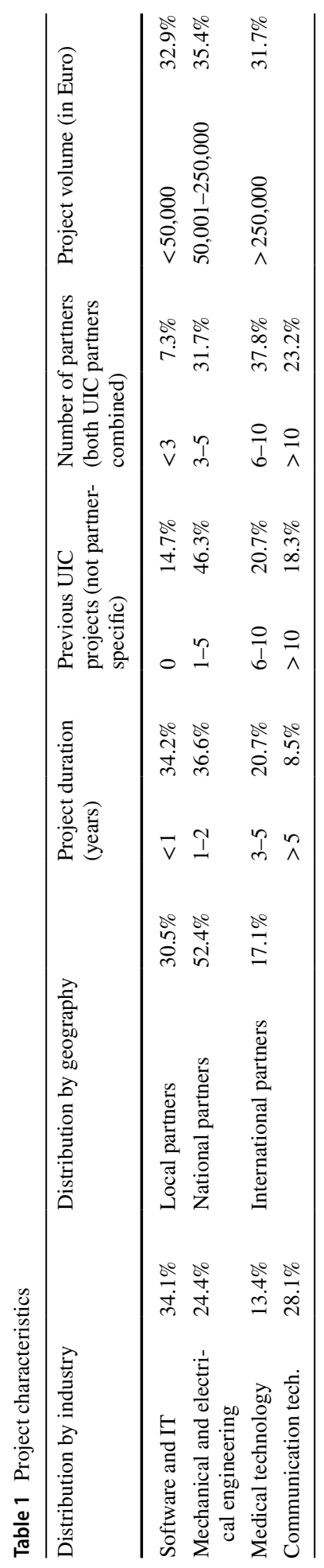


The differences in the perceptions of the degree of innovativeness reflect the degree of shared $R \& D$ project perceptions. We consider innovation as a combination of new means and/or new ends introduced to a market; we therefore suggest that the degree of innovativeness comprises technological and market-related aspects (Kock et al. 2011; Salomo et al. 2007; Schultz et al. 2013b). However, to ensure that both partners could evaluate the specific aspects, we needed to partly modify the items. In the market dimension, we did not include items reflecting business details that are publicly unavailable. Overall, seven items were included in the measurement of innovativeness. The results of a factor analysis suggest a second-order construct for the measurement model to differentiate the two dimensions technological and market innovativeness. We obtained information from both partners to measure the shared $R \& D$ project innovativeness perception. We calculated the difference between both second-order innovativeness scores for each project and then squared the resulting delta. Using an absolute difference score would cause methodological problems for the regression analysis (Edwards and Parry 1993). We compensated for the non-normality in the data by using the logarithmic value for the regression analysis. Finally, we multiplied the value with minus one, in order to obtain our measure of shared perceptions.

UIC project's performance and partners' shared R\&D project innovativeness perception were both assessed in the same survey. We regard this approach as permissible because project planning (university's rating) and project performance (firm's rating) were evaluated independently from each partner and all projects considered for this study were finished within 2 years prior to data collection. Accordingly, we took a certain time lag for the evaluation of performance into consideration.

We used items that combine the content and the quality of the planning activities and relied on the university ratings to calculate the planning intensity. The scale included the comprehensiveness of feasibility studies, the search for alternative solutions, and the clarity of the project objectives (Mora-Valentin et al. 2004; Salomo et al. 2007). Collaborative planning stimulates both partners to participate. We conceptualized collaborative planning with three items: the sharing of the project lead, jointly setting the project objectives, and jointly defining the milestones (Bstieler et al. 2015). The values for each of these three items ranged from 1 (only university) to 7 (only firm). We averaged these values to a Likert-scale from 1 to 7 . We then recoded the scale, so that the value 4 (both contributed equally to planning) represented the highest value, and 1 and 7 represented the lowest value (either one of the partners did all the planning). The university project leader assessed collaborative planning because the university was the one that would most likely plan and realize most of the project work. We tried to reduce common source bias by utilizing the university project leaders as informants of the independent variables and the firm's project leaders as informants of the dependent variable.

Our analysis controls for various attributes to reduce the likelihood of unobserved heterogeneity in the projects. The project duration is measured via the natural logarithm of project days and reflects the project size. In longer projects, the team members have more time to exchange information and to develop a shared perception of the R\&D project. Longer project duration and greater size require more elaborate and formal organizational structures. Thus, larger projects are more likely to show stronger overall levels of project planning than smaller projects (Collyer et al. 2010). Furthermore, we control for number of partners (i.e. number of project team members) in the UIC project. More experience with conducting UIC projects may result in a higher level of agreement between the partners' perceptions and a higher level of project performance (Bstieler et al. 2015, 2017; Sherwood and Covin 2008). We therefore use the number of UIC projects that the 
partners had already participated in as a second control variable. Third, collaboration partners' geographical proximity may influence the efficiency of their collaboration, because long distances limit the amount of potential knowledge spillovers and opportunities for regular intensive communication (Hewitt-Dundas 2013; Mora-Valentin et al. 2004). We distinguish partners' geographical distance in three dimensions: local, national, and international. Finally, from a contingency perspective, a single project's technological field may impact the project controls and the partners' R\&D project perceptions. Projects from different technological fields may vary according to the degree to which they are planned. We control for the effects of the technological field by using dummy variables. The projects in the sample were associated with software and information technology, mechanical and electrical engineering, medical technology, and communication technology.

\section{Results}

\subsection{Descriptive statistics}

In accordance with the conceptual model, we included four constructs in our analysis and assessed constructs' reliability by using Cronbach's alpha. Most of the alphas are in accordance with the recommended cut-off values (i.e., above .70) (Hair et al. 2013). Only technological innovativeness showed a limited reliability of .63, because constructs with a smaller number of items have systematically lower alphas. We subjected the scales to principal component analyses. Only the first eigenvalues were greater than one, which indicates that the constructs are uni-dimensional (Ahire and Devaraj 2001). All of the constructs explain more than $50 \%$ of their items' variance. We designed the innovativeness factor as a second-order construct by separately modeling the market- and technology-related facets. This design reflects the multidimensional nature of this construct. We aggregated the two dimensions of innovativeness by calculating the mean of the two scores. Exploratory factor analysis, which included all of the items comprising the measurement model, showed no cross loadings higher than .30 , with the exception of the cross loading between the planning item 'Comprehensive research into alternative concepts took place' and the technology dimension of the innovativeness construct (.41). However, this cross loading may be acceptable, because the loading on the planning construct is still significantly higher and alternative concepts are likely to be related to technological questions. The Fornell-Larcker criterion was met to verify discriminant validity. Table 2 provides the correlation matrix of the model's constructs, as well as their means and standard deviations.

The assessment of project innovativeness differs between firm and university project leaders. On average, the absolute innovativeness scores of the university ratings of the projects are .51 higher $(\mathrm{t}=-3.22 ; p=.002)$ than the firm ratings of the same projects. Hence, a shared perception existed in some projects, whereas in others the quality of the two partners' interactions was likely to be low, because of the differences in their perceptions. The partners' shared perception of the R\&D project was limited in UIC projects and the impact of the misalignment is a relevant issue for analysis. Furthermore, the descriptive statistics reveal that the planning process's intensity was relatively high $($ mean $=5.76)$ on average and that both partners were involved in many of the projects. Table 2 describes some of the characteristics of the projects that the universities and the firm conducted jointly. On average, the projects were relatively long-term (i.e., more than 2 years). Most of the projects were conducted by partners from the same country, because a regional R\&D center of the 


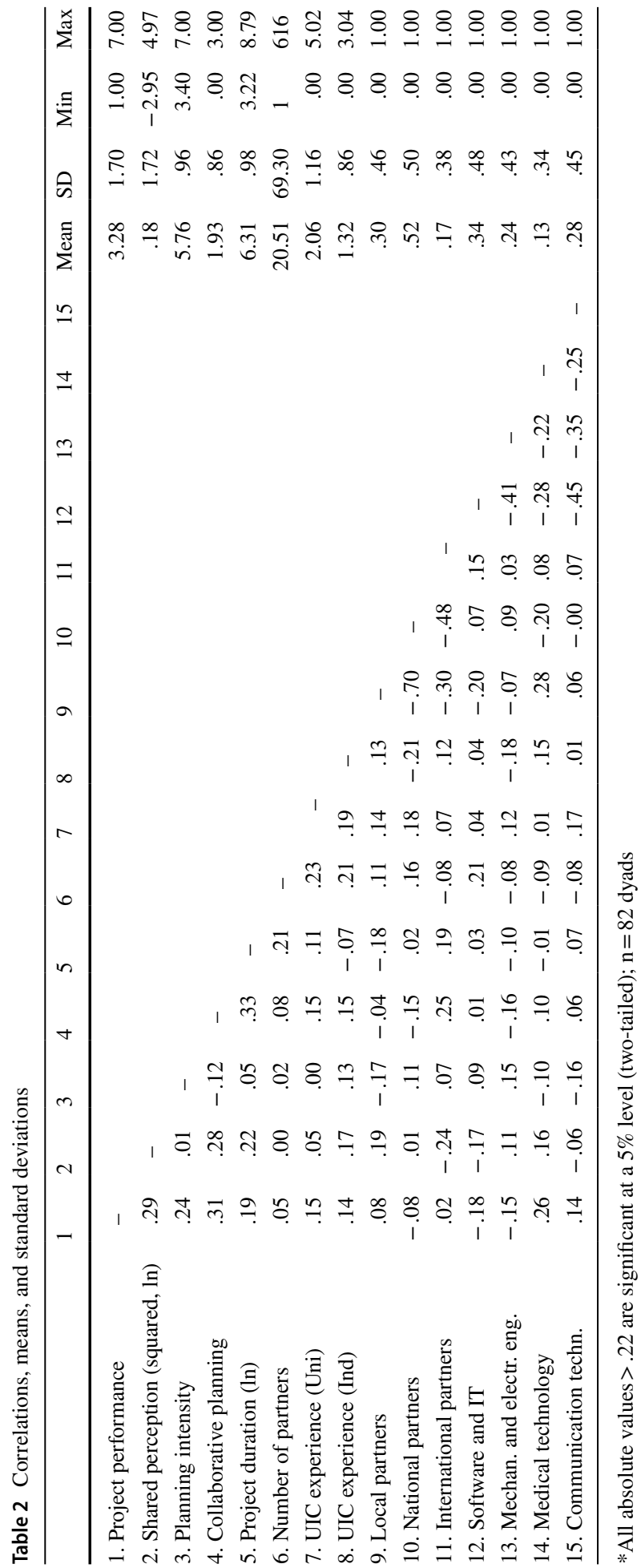


focal firm led most of the university R\&D projects. UIC projects with local partners exhibit higher degrees of shared perceptions, which may allow partners to replace the formal planning process with a more informal control mechanism. Both partner groups were relatively experienced with conducting UIC. However, the level of experience was unevenly distributed as some individuals had already been involved in many projects, but others not.

\subsection{Effects of planning on partners' shared R\&D project perceptions}

We tested the hypotheses using two sets of hierarchical OLS regressions. The first set assessed the hypothesized effects of planning intensity and collaborative planning on partners' shared R\&D project innovativeness perceptions (see Table 3). The second set addressed the shared perceptions' effects on project performance (see Table 4). In Table 3, model 1 shows the regression of partners' shared perceptions on the control variables. Model 2 includes the hypothesized effects of planning intensity and collaborative planning. Model 3 introduces the interaction effects of both characteristics. To test the interaction effect, we use the centered variables' multiplication terms (Aiken et al. 1991). Both models 2 and 3 increase the adjusted $\mathrm{R}^{2}$ significantly.

In Table 3, the results of model 1 (only controls) indicate that the partners' shared R\&D project perceptions are positively associated with the project duration $(b=.64, p=.010)$. Thus, UIC projects that lasted two or more years gave partners sufficient time to develop a shared perception and trust in the collaboration partner. The significant effect of the firm's prior collaboration experiences on partners' development of a shared perception $(b=.52$, $p=.016)$ also indicates the positive relationship between experience and a shared $\mathrm{R} \& \mathrm{D}$ project perception. The effect of university researchers' prior experience with UIC may be negligible, because the sample includes a substantial number of highly experienced

Table 3 Effects on the shared R\&D project perceptions

\begin{tabular}{lccc}
\hline Shared perception (shared, ln) & $(1)$ & $(2)$ & $(3)$ \\
\hline Project duration (ln) & $.64(.24)^{* *}$ & $.49(.23)^{*}$ & $.52(.22)^{*}$ \\
Number of partners & $.00(.00)$ & $.00(.00)$ & $.00(.00)+$ \\
Software and IT & $.13(.39)$ & $.17(.36)$ & $.23(.34)$ \\
Mechanical and electrical engineering & $.92(.58)$ & $1.02(.57)+$ & $.82(.55)$ \\
Medical technology & $.61(.58)$ & $.51(.53)$ & $.44(.55)$ \\
UIC experience (university, ln) & $.05(.16)$ & $.02(.15)$ & $.04(.15)$ \\
UIC experience (industry, ln) & $.52(.21)^{*}$ & $.45(.20)^{*}$ & $.41(.20)^{*}$ \\
National partners & $-.35(.42)$ & $-.35(.40)$ & $-.38(.38)$ \\
International partners & $-1.77(.50)^{* *}$ & $-2.01(.50)^{* *}$ & $-2.04(.48)^{* *}$ \\
Planning intensity & & $.01(.18)$ & $.06(.17)$ \\
Collaborative planning & & $.58(.22)^{* *}$ & $.50(.22)^{*}$ \\
Planning intensity $\times$ collaborative planning & .257 & & $.49(.23)^{*}$ \\
$\mathrm{R}^{2}$ & .164 & .326 & .364 \\
Adjusted R & & .220 & .253 \\
$\Delta \mathrm{R}^{2}$ & .257 & $.069 *$ & $.038^{* *}$ \\
\hline
\end{tabular}

$+p<.1 ; * p<.05$; ** $p<.01$ (two tailed); unstandardized regression coefficients with standard errors in parentheses; $\mathrm{n}=82$ dyads 
Table 4 Effects on project performance

\begin{tabular}{lccc}
\hline Project performance & $(1)$ & $(2)$ & $(3)$ \\
\hline Project duration (ln) & $.31(.20)$ & $.14(.20)$ & $-.01(.20)$ \\
Number of partners & $.00(.00)$ & $.00(.00)$ & $.00(.00)$ \\
Software and IT & $-.78(.52)$ & $-.81(.51)$ & $-1.04(.49)^{*}$ \\
Mechanical and electrical engineering & $-.65(.52)$ & $-.88(.51)+$ & $-1.04(.50)^{*}$ \\
Medical technology & $.75(.64)$ & $.59(.63)$ & $.54(.56)$ \\
UIC experience (university, ln) & $.12(.16)$ & $.10(.16)$ & $.05(.16)$ \\
UIC experience (industry, ln) & $.18(.21)$ & $.05(.21)$ & $-.12(.21)$ \\
National partners & $.02(.48)$ & $.11(.46)$ & $-.10(.39)$ \\
International partners & $.06(.59)$ & $.51(.59)$ & $.14(.58)$ \\
Planning intensity & & & $.66(.18)^{* *}$ \\
Collaborative planning & & & $.49(.23)^{*}$ \\
Planning intensity $\times$ collaborative planning & & $.21(.29)$ \\
Shared perception (squared, ln) & .162 & $.25(.10)^{*}$ & $.22(.10)^{*}$ \\
$\mathrm{R}^{2}$ & .058 & .212 & .351 \\
Adjusted R & & .101 & .227 \\
$\Delta \mathrm{R}^{2}$ & .162 & $.050^{*}$ & $.139^{* *}$ \\
\hline
\end{tabular}

$+p<.1 ; * p<.05 ; * * p<.01$ (two tailed); unstandardized regression coefficients; standard errors in parentheses; $\mathrm{n}=82$ dyads

academics, which is a special characteristic. Partners' shared R\&D project perceptions are lower in international partnerships $(b=-1.77, p=.001)$. This difference may reflect the challenges associated with global R\&D collaboration.

Model 2 in Table 3 includes the independent variables (i.e., collaborative planning and planning intensity). Contrary to expectations, the average effect of planning intensity is not significant $(b=.01, p=.949)$. The average effect of collaborative planning is, however, positive and significant $(b=.58, p=.009)$. Integrating the interaction effects of the independent variables in model 3 increases the model fit and the explained variance (adjusted $\mathrm{R}^{2}=.253$ ) significantly. The results reveal a significant positive interaction between planning intensity and collaborative planning $(\mathrm{b}=.49, p=.034)$. This finding supports hypothesis 4. Intense up-front planning only influences the partners' shared perception of the $R \& D$ project if the university and the firm jointly engage in the decision-making processes. Accordingly, the planning intensity (i.e., the formal control) and the collaborative planning process (i.e., the social control) are not a substitute for each other, but instead function as re-enforcing complements.

Figure 3 displays the simple slopes of this interaction effect by using a low and a high value of the moderating variable collaborative planning (i.e., one standard deviation below or above the mean). The simple slopes show that if the firm and the university do not plan an R\&D project jointly (i.e., low collaborative planning), the formal planning process (i.e., planning intensity) decreases the partners' shared perceptions. Thus, partners should combine planning intensity (i.e., planning process's formal control) with collaborative planning (i.e., the interaction's social control). If only one partner engages in planning, the UIC partners are unlikely to develop a shared perception. Instead, the potential differences in the partners' perceptions will grow even further apart. Vice versa, a high level of collaborative planning helps increase the shared perception for higher levels of planning intensity. 


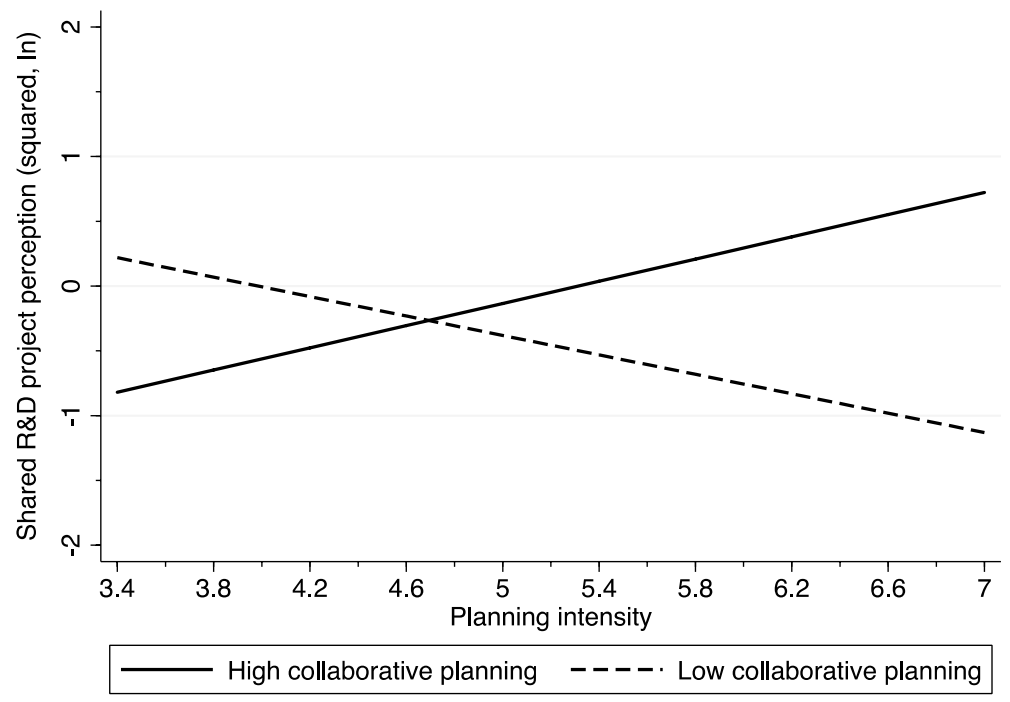

Fig. 3 Simple slope analysis

\subsection{Effects of partners' shared R\&D project perceptions on project performance}

Table 4 displays the results of the effects of partners' shared perceptions on project performance. Model 1, containing the control variables, shows that none of them is significantly related to project performance. Model 2 indicates that partners' shared perceptions are positively related to project performance $(b=.25, p=.014)$. The results of model 3 show that planning intensity and collaborative planning during the planning process both are significantly related to project performance $(b=.66, p=.001$, and $b=.49, p=.039$, respectively). However, we do not find a significant interaction effect ( $b=-.21, p=.477$ ). The data supports the hypothesis that UIC project performance increases with higher levels of partners' shared R\&D project innovativeness perceptions. Overall, model 3 explains $35.1 \%$ of the variance in project performance. Both models 2 and 3 increase the adjusted $\mathrm{R}^{2}$ significantly.

\subsection{Robustness checks}

In order to test the results' robustness, we applied alternative performance measures and tested additional control variables. First, we used technology success, patents, and satisfaction as alternative performance indicators. We measured technology success with four items: whether new technologies were developed, if patents and/or scientific publications were generated, and if the project improved the firm's scientific reputation. We used the actual number of patent applications as the indicator for patents. Satisfaction addressed with five items the extent to which the firm's expectations with respect to universities' competencies, cost-efficiency, market access, information supply, and regulatory access were met. For all alternative performance measures, the relevant main effect of UIC partners' shared perception on project performance remained stable and significant. 
Second, we included formal project management, project size, and top management support as additional control variables in the model. Formal project management was measured with the intensity of the usage of project management tools such as milestone plans, milestone trend analysis, staff and resource plans, budget plans, risk management, and quality management. The project budget in Euro indicates the project size. Project size and project duration (the control variable in the main empirical model) correlated highly $(r=.76)$ and the results reported were the same, if we use project size or both variables as control variables. Top management support captured the intensity of top management involvement in the project-planning phase. For all alternative control variables, the relevant main effects on UIC partners' shared perceptions and the effects on UIC project performance remained stable and significant. Hence, we consider our regression results being robust.

\subsection{Summary of findings}

Overall, the empirical findings support three of the four hypotheses. Partners' shared R\&D project innovativeness perceptions reinforce UIC projects' performance (H1). The results do not support the notion that planning intensity has a direct effect on partners' shared R\&D project innovativeness perceptions (H2), but support the direct effect of collaborative planning (H3). However, both independent variables are relevant for shared R\&D project innovativeness perceptions, because they interact. In accordance with organizational control theory, planning intensity (i.e., formal control) and collaborative planning (i.e., social control) complement each other in UIC projects (H4). The effect of planning on performance is reinforced if both partners are involved. If only one partner (e.g., the university) engages in planning, partners' shared $R \& D$ project innovativeness perceptions will decrease. Vice versa, if both partners are involved, partners' shared perceptions and the project performance will increase.

\section{Discussion}

The current study contributes to research on the coordination processes that occur in UIC projects (Bstieler and Hemmert 2010; Perkmann and Walsh 2007). Using a sample of 164 UIC project leaders in 82 dyads, we studied how the intensity of the planning process and the social interactions that occur in the planning process are related to partners' shared $\mathrm{R} \& \mathrm{D}$ project perceptions and, finally, to UIC project's performance.

\subsection{Theoretical implications}

The results show that the different thought worlds of UIC partners (Dougherty 1992) can cause differences in their perceptions of the targeted degree of innovativeness, which, in turn, hampers project performance. Heider's balance theory indicates that, in this context, the relationship quality will be low, conflicts are likely to prevail, and coordinating the required inter-organizational responsibilities will be difficult. This result complements previous research findings suggesting that, in technology alliances, both partners should agree on a common aspiration level and that explorative alliances, such as UIC projects, should utilize an interactive problem-solving process (Bishop et al. 2011). Such a high-quality 
relationship will have a central impact on the UIC technology transfer's effectiveness (Bruneel et al. 2010; Santoro and Gopalakrishnan 2001).

An intensive and interactive planning process has a significant impact on partners' shared $R \& D$ project innovativeness perceptions and therefore affects project performance. Partners will only develop a shared perception of the innovative R\&D project and succeed in its execution, if both sides are involved in the planning process. If a firm and a university wish to collaborate effectively, they must clarify the project content and systematically process the information in the planning phase. This finding is in line with the results of prior empirical studies on the impacts of planning and managerial direction on new product development projects' performance (Gama et al. 2017; Sethi and Iqbal 2008) and on interorganizational development teams (Bstieler and Hemmert 2010). The more concrete and transparent plans are with regard to the goals, timelines, hurdles, and responsibilities, the greater the performance will be. We show that partners' joint planning process is important, because this allows formal and social controls to interact. UIC projects in which the firm managers define the overall objective and the university researchers plan and execute the project instead of collaborating (i.e., contract research) are not optimal. Such a setup bears a major risk in that the university researchers' interpretation of the project may differ from the firm managers' perception. This result also contributes to the literature on organizational control theory by showing that formal and social organizational controls cannot substitute one another, but are complementary elements (Kirsch 1996; Rijsdijk and van den Ende 2011).

Managers can efficiently assess the quality of the relationship by assessing the partners' shared perceptions of the degree of innovativeness. Differences in the partners' perceptions also provide information required about the potential benefits, barriers, and management approaches associated with different degrees of innovativeness. This study thus helps explain how the degree of innovativeness influences UIC project performance (Kock et al. 2011; Szymanski et al. 2007). Highly innovative UIC projects have enormous technological and market potential, but can also face serious challenges regarding the successful implementation of their results (Hottenrott and Lopes-Bento 2016; Wirsich et al. 2016).

\subsection{Managerial implications}

Our study has valuable implications for UIC managers. Both partners should aspire a shared perception of the R\&D project as it is crucial for UIC success. UIC managers can easily assess their perceived degree of innovativeness in different phases of the UIC project. Monitoring and open communication could ensure continuous alignment of partners' R\&D project perceptions. UIC project managers should address their differences in perception, which may reflect, or eventually cause, a low-quality relationship.

Both partners have to invest in the project's initialization phase. Intensive up-front planning helps them cope with the uncertainty of new technological and market concepts. Joint feasibility studies could prepare for the challenges the UIC project aims to address and provide information regarding the probability that specific concepts will succeed. If the first feasibility study is successful, firms could finance embryonic projects and later prolong them. Additionally, publicly financed research often supports UIC externally. In this case, a firm can achieve cost savings, but it also has reduced control over the resulting intellectual property rights (Henttonen et al. 2016).

However, overly intensive planning can result in research projects' strong formalization, which may have negative effects on the creativity and the flexibility of the R\&D 
partners (Du et al. 2014). Because UIC projects focus on learning and innovation, creativity and exploration are essential for their success. Hence, partners must establish a balance between firms' need for formalization and universities' need for freedom (Tartari and Breschi 2012). Informal approaches may help ensure a shared perception of the R\&D project. A straightforward, easy, and informal approach could be to form teams comprising members of both organizations. The co-location of firm and university team members could further establish an environment characterized by intensive interactions and the communication of tacit information (Song et al. 2007). Joint contributions and close collaboration can also help coordinate partners' contributions.

The positive effects of project duration, local partnerships, and prior experiences with UIC on partners' shared R\&D project innovativeness perception emphasize the need for partners' trustworthy and long-term collaboration (Bstieler et al. 2015). Strategic alliances may induce firms to adopt a stronger scientific orientation and universities to embrace a stronger entrepreneurial orientation (Cheng and Huizingh 2014; Jain et al. 2009). Given the more long-term interaction, partners can be more transparent regarding their competences, needs, and processes, which will help increase their shared perceptions of the R\&D project.

Scholars agree that public support programs benefit firms' R\&D endeavors (Dumont 2017; Rosenbloom and Ginther 2017), but technology transfer projects need to be systematically managed to bridge UIC partners' cognitive distance and to increase partners' shared perception. Furthermore, firms which have rarely worked with science-based partners also face an increased risk of perception differences with universities, due to their lack of collaboration experience (Bruneel et al. 2010). Consequently, technology policy should promote long-term research alliances to help partners adjust their expectations and activities in order to increase chances for shared R\&D project perceptions. In addition, universities' TTOs, whose purpose is to surmount organizational boundaries, can help partners overcome their relational and structural barriers by making the collaboration partners' requirements transparent (Hall et al. 2001; O'Kane et al. 2015).

A TTO's range of services usually includes the initialization of university-industry relationships, the transfer of university researchers' findings into public and/or commercial use, and the safeguarding of financial resources (e.g., research funding by public or industrial sources; royalty incomes be licensing activities) (Fitzgerald and Cunningham 2016). TTOs can help set up the management competencies needed for smooth collaborative interactions, the exploitation of university researchers' intellectual property, and commercialization activities (Okamuro and Nishimura 2013). Younger scholars may specifically profit from such transparent structures and previous experiences by forming their later collaborative agreements accordingly. In their crucial role, TTOs may help reduce obstacles related to asymmetric information, meaning that they can help strengthen firm managers' confidence in university researchers' expertise and output quality, as well as adjust university scientists' expectations concerning the true value of their research findings and inventions, which otherwise often remains vague (Siegel et al. 2007). Moreover, TTOs may evolve as dedicated knowledge hubs for UIC experience, therefore establishing reliable networks and further facilitating knowledge and technology transfer (Hülsbeck et al. 2013; Sherwood and Covin 2008). Over time, multiple collaboration will provide a better understanding of partners' peculiarities. Furthermore, UIC experience, even not partners-specific experiences, will mitigate cognitive dissonances and help align expectations (Muscio and Pozzali 2013). Moreover, pre-projects could help evaluate the potentials and risks associated with UIC projects and requirements needed to fulfil the project goals (Morandi 2013). 


\section{Limitations and future research}

This study has limitations that may, however, guide future research. First, the sample contains UIC projects from a single multinational firm conducted with several universities worldwide. On the one hand, this approach allows us to control for firm peculiarities and, therefore, to focus on partners' project-specific shared perceptions. On the other hand, this study's results may only be generalizable to a limited extent.

Second, we use the firm rating of project performance as the dependent variable and the university ratings as the independent constructs. Although we could reduce common source biases, bias may still be present, because the project leaders themselves evaluated the performance of their UIC project. However, we assume that the university is responsible for the main workload, which means the firm managers (i.e., the customer) are still a valid source to assess UIC project performance.

Third, we only addressed the assessment of shared R\&D project innovativeness perceptions at a single point in time. A longitudinal study design would help evaluate the development of partners' shared $R \& D$ project perception over time and to draw conclusions about its impact on UIC project performance.

Fourth, this study explains the relevant effects of collaborative research on performance from a firm's perspective. As universities also benefit from joint research with industrial partners (Muscio and Pozzali 2013), scholars should also assess the project performance from the academic perspective. The performance criteria could be related to publications or patents, the evaluation of the generated knowledge and the possibilities of future research projects. A comparison could provide interesting insights into the deviations that resulted due to the applied management practices. Further, it would be relevant to learn more about the actual knowledge generated in UIC projects and how the outcomes of the early phases of the innovation process contribute to future follow-up developments in the firm (Wirsich et al. 2016).

This study shows that relationship characteristics are an important research area of interorganizational development processes. If two thought worlds collide, shared R\&D project perceptions become an important success factor. Although the present study focuses on planning and on various control variables as the determinants of the shared $R \& D$ project perceptions, other independent variables may also be relevant. For instance, if the partners share a cognitive (Filiou and Massini 2018; Nooteboom et al. 2007) or methodological background (Sampson 2007), if the project team is co-located, and if team members intensively communicate, they might also share a perception (Hoegl and Proserpio 2004). The projects' starting conditions could also be relevant; future research should therefore focus on the initialization process (i.e., how partners find each other and how R\&D projects are defined).

According to Heider's balance theory, partners' shared perceptions are related to a highquality relationship and well-working coordination. These issues explain the positive effect of partners' shared $\mathrm{R} \& \mathrm{D}$ project innovativeness perception on project performance. This finding requires researchers to consider the potential mediators of this performance effect. Future research should therefore directly address the role of trust and commitment by incorporating the quality of coordination into the analysis. Bstieler et al. (2015) provided a comprehensive approach in this direction. 


\section{Conclusion}

In this study, we focus on UIC partners' distinct organizational backgrounds and their socialization with different thought worlds, which may affect their management approaches and their goals pursued in collaborative R\&D projects (Dougherty 2008; Heider 1965). Hence, partners' perceptions of the joint R\&D challenge to solve may diverge which may impede partners' coordination, increase tensions during collaboration and pose successful UIC project outcomes at risk (Filiou and Massini 2018; Nooteboom et al. 2007).

First, we contribute the construct of partners' shared R\&D project perceptions to UIC literature. Second, we contribute to control theory by investigating the effects of formal control (i.e., planning intensity) and social control (i.e., collaborative planning) on partners' shared R\&D project innovativeness perceptions and their effects on UIC project performance.

We use dyadic UIC project assessments of 164 UIC project managers (i.e., firm's managers and universities' professors) of 82 projects and find that partners' shared R\&D project innovativeness perceptions increase UIC project performance. We show that collaborative planning as a social control positively affects partners' shared R\&D project perceptions and that planning intensity as a formal control complements collaborative planning's effect. Accordingly, partners' joint engagement in interactive and intensive planning will help them develop a shared perception of the R\&D challenge to solve in the UIC project, and ultimately, to increase UIC project performance.

Acknowledgements Open Access funding provided by Projekt DEAL.

Open Access This article is licensed under a Creative Commons Attribution 4.0 International License, which permits use, sharing, adaptation, distribution and reproduction in any medium or format, as long as you give appropriate credit to the original author(s) and the source, provide a link to the Creative Commons licence, and indicate if changes were made. The images or other third party material in this article are included in the article's Creative Commons licence, unless indicated otherwise in a credit line to the material. If material is not included in the article's Creative Commons licence and your intended use is not permitted by statutory regulation or exceeds the permitted use, you will need to obtain permission directly from the copyright holder. To view a copy of this licence, visit http://creativecommons.org/licenses/by/4.0/.

\section{Appendix: Measurement}

Technological innovativeness* $(\alpha=.63)$ (based on Kock et al. 2011; Schultz et al. 2013b).

- A completely new technology/principle is used in the project.

- The project has the potential to create a performance jump.

- The project has the potential to cause existing technologies to be substituted and become obsolete.

Market innovativeness $*(\alpha=$.74) (based on Kock et al. 2011; Schultz et al. 2013b).

- The innovation addresses a completely new customer benefit.

- The innovation causes intensive changes in customer behavior and processes.

- The customer has to build up new competences to use the innovation. 
- Steps in the value chain become obsolete or are significantly changed (e.g. B2B-internet-markets vs. classical sales).

Planning intensity ( $\alpha=$.77) (based on Mora-Valentin et al. 2004; Salomo et al. 2007).

- The technical feasibility was analyzed as well as possible.

- Clear project requirements were defined.

- An intensive analysis of existing products and technologies was performed.

- All relevant aspects for the evaluation of the project were completely covered within the planning phase.

- The basis of data for the planning phase is considered to be sound and reliable.

Collaborative planning ( $\alpha=$.74) (based on Bstieler et al. 2015).

- Who had the project lead?**

- Who defined project objectives?**

- Who defined milestones?**

Project performance $(\alpha=.80)$ (based on Griffin and Page 1993; Schultz et al. 2013b; Verworn 2009).

- The project had a significant positive impact on profits.

- We gained competitive advantage through the project.

- We acquired new customers through the project.

*The logarithm of the squared difference score $\ln$ (university-industry) ${ }^{2}$ multiplied by $(-1)$ is used as an indicator for the shared perception of the $R \& D$ project

**Values ranged from 1 (only university) to 7 (only firm) and were averaged to a Likertscale from 1 to 7 . We recoded this scale into the following: values 1 and 7 were recoded to 0 ; values 2 and 6 were recoded to 1; values 3 and 5 were recoded to 2; value 4 was recoded to 3 . Hence, the value 4 (both partners contributed equally to planning) represented the highest value and 1 and 7 represented the lowest value (either one of the partners did all the planning)

\section{References}

Ahire, S. L., \& Devaraj, S. (2001). An empirical comparison of statistical construct validation approaches. IEEE Transactions on Engineering Management, 48(3), 319-329.

Aiken, L. S., West, S. G., \& Reno, R. R. (1991). Multiple regression: Testing and interpreting interactions. Thousand Oaks, CA: Sage.

Albats, E., Fiegenbaum, I., \& Cunningham, J. A. (2018). A micro level study of university industry collaborative lifecycle key performance indicators. Journal of Technology Transfer, 43(2), 389-431.

Baba, Y., Shichijo, N., \& Sedita, S. R. (2009). How do collaborations with universities affect firms' innovative performance? The role of "Pasteur scientists" in the advanced materials field. Research Policy, 38(5), 756-764.

Balogun, J., \& Johnson, G. (2004). Organizational restructuring and middle manager sensemaking. Academy of Management Journal, 47(4), 523-549.

Belderbos, R., Cassiman, B., Faems, D., Leten, B., \& Van Looy, B. (2014). Co-ownership of intellectual property: Exploring the value-appropriation and value-creation implications of co-patenting with different partners. Research Policy, 43(5), 841-852. 
Bengtsson, L., Lakemond, N., Lazzarotti, V., Manzini, R., Pellegrini, L., \& Tell, F. (2015). Open to a select few? Matching partners and knowledge content for open innovation performance. Creativity and Innovation Management, 24(1), 72-86.

Bercovitz, J., \& Feldman, M. P. (2007). Fishing upstream: Firm innovation strategy and university research alliances. Research Policy, 36(7), 930-948.

Bishop, K., D’Este, P., \& Neely, A. (2011). Gaining from interactions with universities: Multiple methods for nurturing absorptive capacity. Research Policy, 40(1), 30-40.

Boardman, P. C., \& Ponomariov, B. L. (2009). University researchers working with private companies. Technovation, 29(2), 142-153.

Bozeman, B., Fay, D., \& Slade, C. P. (2013). Research collaboration in universities and academic entrepreneurship: the state-of-the-art. Journal of Technology Transfer, 38, 1-67.

Bruneel, J., D’Este, P., \& Salter, A. (2010). Investigating the factors that diminish the barriers to universityindustry collaboration. Research Policy, 39(7), 858-868.

Bstieler, L., \& Hemmert, M. (2010). Increasing learning and time efficiency in interorganizational new product development teams. Journal of Product Innovation Management, 27(4), 485-499.

Bstieler, L., \& Hemmert, M. (2015). The effectiveness of relational and contractual governance in new product development collaborations: Evidence from Korea. Technovation, 45-46, 29-39.

Bstieler, L., Hemmert, M., \& Barczak, G. (2015). Trust Formation in University-Industry Collaborations in the U.S. Biotechnology Industry: IP Policies, Shared Governance, and Champions. Journal of Product Innovation Management, 32(1), 111-121.

Bstieler, L., Hemmert, M., \& Barczak, G. (2017). The changing bases of mutual trust formation in interorganizational relationships: A dyadic study of university-industry research collaborations. Journal of Business Research, 74, 47-54.

Buenger, V., Daft, R. L., Conlon, E. J., \& Austin, J. (1996). Competing values in organizations: Contextual influences and structural consequences. Organization Science, 7(5), 557-576.

Cannella, A. A., Park, J. H., \& Lee, H. U. (2008). Top management team functional background diversity and firm performance: Examining the roles of team member colocation and environmental uncertainty. Academy of Management Journal, 51(4), 768-784.

Cassiman, B., Di Guardo, M. C., \& Valentini, G. (2010). Organizing links with science: Cooperate or contract? A project-level analysis. Research Policy, 39(7), 882-892.

Chandy, R. K., \& Tellis, G. J. (1998). Organizing for radical product innovation: The overlooked role of willingness to cannibalize. Journal of Marketing Research, 35(4), 474-487.

Cheng, C. C. J., \& Huizingh, E. (2014). When is open innovation beneficial? The role of strategic orientation. Journal of Product Innovation Management, 31(6), 1235-1253.

Collyer, S., Warren, C., Hemsley, B., \& Stevens, C. (2010). Aim, fire, aim-project planning styles in dynamic environments. Project Management Journal, 41(4), 108-121.

Das, T. K., \& Teng, B.-S. (2001). Trust, control, and risk in strategic alliances: An integrated framework. Organization Studies, 22(2), 251-283.

de Rassenfosse, G., Palangkaraya, A., \& Webster, E. (2016). Why do patents facilitate trade in technology? Testing the disclosure and appropriation effects. Research Policy, 45(7), 1326-1336.

D'Este, P., \& Perkmann, M. (2011). Why do academics engage with industry? The entrepreneurial university and individual motivations. Journal of Technology Transfer, 36, 316-339.

Dougherty, D. (1992). Interpretive barriers to successful product innovation in large firms. Organization Science, 3(2), 179-202.

Dougherty, D. (2008). Bridging social constraint and social action to design organizations for innovation. Organization Studies, 29(3), 415-434.

Du, J., Leten, B., \& Vanhaverbeke, W. (2014). Managing open innovation projects with science-based and market-based partners. Research Policy, 43(5), 828-840.

Dumont, M. (2017). Assessing the policy mix of public support to business R\&D. Research Policy, 46(10), 1851-1862.

Edwards, J. R., \& Parry, M. E. (1993). On the use of polynomial regression equations as an alternative to difference scores in organizational research. Academy of Management Journal, 36(6), 1577-1613.

Eisenhardt, K. M. (1985). Control: Organizational and economic approaches. Management Science, 31(2), 134-149.

Feller, I., Ailes, C. P., \& Roessner, J. D. (2002). Impacts of research universities on technological innovation in industry: Evidence from engineering research centers. Research Policy, 31(3), 457-474.

Filiou, D., \& Massini, S. (2018). Industry cognitive distance in alliances and firm innovation performance. $R \& D$ Management, 48(4), 422-437.

Fitzgerald, C., \& Cunningham, J. A. (2016). Inside the university technology transfer office: mission statement analysis. Journal of Technology Transfer, 41(5), 1235-1246. 
Florén, H., \& Frishammar, J. (2012). From preliminary ideas to corroborated product definitions: Managing the front end of new product development. California Management Review, 54(4), 20-43.

Gama, F., Sjödin, D. R., \& Frishammar, J. (2017). Managing interorganizational technology development: Project management practices for market- and science-based partnerships. Creativity and Innovation Management, 26(2), 115-127.

George, G., Kotha, R., \& Zheng, Y. (2008). Entry into insular domains: A longitudinal study of knowledge structuration and innovation in biotechnology firms. Journal of Management Studies, 45(8), $1448-1474$.

Gerwin, D. (2004). Coordinating new product development in strategic alliances. Academy of Management Review, 29(2), 241-257.

Gesing, J., Antons, D., Piening, E. P., Rese, M., \& Salge, T. O. (2015). Joining forces or going it alone? On the interplay among external collaboration partner types, interfirm governance modes, and internal R\&D. Journal of Product Innovation Management, 32(3), 424-440.

Griffin, A., \& Page, A. L. (1993). An interim-report on measuring product development success and failure. Journal of Product Innovation Management, 10(4), 291-308.

Gubitta, P., Tognazzo, A., \& Destro, F. (2016). Signaling in academic ventures: the role of technology transfer offices and university funds. Journal of Technology Transfer, 41(2), 368-393.

Guzzini, E., \& Iacobucci, D. (2017). Project failures and innovation performance in university-firm collaborations. Journal of Technology Transfer, 42(4), 865-883.

Hagedoorn, J., Link, A. N., \& Vonortas, N. S. (2000). Research Partnerships. Research Policy, 29(4/5), 567-586.

Hair, J. F., Black, W. C., Babin, B. J., \& Anderson, R. E. (2013). Multivariate data (7th ed.). Harlow: Pearson Education Limited.

Hall, B. H., Link, A. N., \& Scott, J. T. (2001). Barriers inhibiting industry from partnering with universities: Evidence from the advanced technology program. Journal of Technology Transfer, 26, 87-98.

Heider, F. (1965). The Psychology of Interpersonal Relations (4th ed.). New York: Wiley.

Henttonen, K., Hurmelinna-Laukkanen, P., \& Ritala, P. (2016). Managing the appropriability of R\&D collaboration. $R \& D$ Management, 46, 145-158.

Hewitt-Dundas, N. (2013). The role of proximity in university-business cooperation for innovation. Journal of Technology Transfer, 38(2), 93-115.

Hoegl, M., \& Gemünden, H. G. (2001). Teamwork quality and the success of innovative projects: A theoretical concept and empirical evidence. Organization Science, 12(4), 435-449.

Hoegl, M., \& Parboteeah, K. P. (2006). Team goal commitment in innovative projects. International Journal of Innovation Management, 10(03), 299-324.

Hoegl, M., \& Proserpio, L. (2004). Team member proximity and teamwork in innovative projects. Research Policy, 33(8), 1153-1165.

Hottenrott, H., \& Lopes-Bento, C. (2016). R\&D partnerships and innovation performance: Can there be too much of a good thing? Journal of Product Innovation Management, 33(6), 773-794.

Hülsbeck, M., Lehmann, E. E., \& Starnecker, A. (2013). Performance of technology transfer offices in Germany. Journal of Technology Transfer, 38(3), 199-215.

Jain, S., George, G., \& Maltarich, M. (2009). Academics or entrepreneurs? Investigating role identity modification of university scientists involved in commercialization activity. Research Policy, $38(6), 922-935$.

Johnson, W. H. A. (2011). Managing university technology development using organizational control theory. Research Policy, 40(6), 842-852.

Kelley, D., \& Lee, H. (2010). Managing innovation champions: The impact of project characteristics on the direct manager role. Journal of Product Innovation Management, 27(7), 1007-1019.

Kirsch, L. J. (1996). The management of complex tasks in organizations: Controlling the systems development process. Organization Science, 7(1), 1-21.

Kleinschmidt, E. J., de Brentani, U., \& Salomo, S. (2007). Performance of global new product development programs: A resource-based view. Journal of Product Innovation Management, 24(5), 419-441.

Kobarg, S., Stumpf-Wollersheim, J., \& Welpe, I. M. (2018). University-industry collaborations and product innovation performance: The moderating effects of absorptive capacity and innovation competencies. Journal of Technology Transfer, 43(6), 1696-1724.

Kock, A., Gemünden, H. G., Salomo, S., \& Schultz, C. (2011). The mixed blessings of technological innovativeness for the commercial success of new products. Journal of Product Innovation Management, 28(S1), 28-43.

Lacetera, N. (2009). Different missions and commitment power in R\&D organizations: Theory and evidence on industry-university alliances. Organization Science, 20(3), 565-582. 
Lafuente, E., \& Berbegal-Mirabent, J. (2019). Assessing the productivity of technology transfer offices: An analysis of the relevance of aspiration performance and portfolio complexity. Journal of Technology Transfer, 44(3), 778-801.

Lawson, B., Petersen, K. J., Cousins, P. D., \& Handfield, R. B. (2009). Knowledge sharing in interorganizational product development teams: The effect of formal and informal socialization mechanisms. Journal of Product Innovation Management, 26(2), 156-172.

Lazzarotti, V., Manzini, R., Nosella, A., \& Pellegrini, L. (2016). Collaborations with scientific partners: The mediating role of the social context in fostering innovation performance. Creativity and Innovation Management, 25(1), 142-156.

Lhuillery, S., \& Pfister, E. (2009). R\&D cooperation and failures in innovation projects: Empirical evidence from French CIS data. Research Policy, 38(1), 45-57.

Li, Y. A., Xie, E., Teo, H. H., \& Peng, M. W. (2010). Formal control and social control in domestic and international buyer-supplier relationships. Journal of Operations Management, 28(4), 333-344.

Lim, B. C., \& Klein, K. J. (2006). Team mental models and team performance: A field study of the effects of team mental model similarity and accuracy. Journal of Organizational Behavior, 27(4), 403-418.

Maietta, O. W. (2015). Determinants of university-firm R\&D collaboration and its impact on innovation: A perspective from a low-tech industry. Research Policy, 44(7), 1341-1359.

Maitlis, S. (2005). The social processes of organizational sensemaking. Academy of Management Journal, $48(1), 21-49$.

Michel, A. A. (2007). A distributed cognition perspective on newcomers' change processes: The management of cognitive uncertainty in two investment banks. Administrative Science Quarterly, 52(4), 507-557.

Morandi, V. (2013). The management of industry-university joint research projects: how do partners coordinate and control R\&D activities? Journal of Technology Transfer, 38(2), 69-92.

Mora-Valentin, E. M., Montoro-Sanchez, A., \& Guerras-Martin, L. A. (2004). Determining factors in the success of R\&D cooperative agreements between firms and research organizations. Research Policy, $33(1), 17-40$.

Muscio, A. (2010). What drives the university use of technology transfer offices? Evidence from Italy. Journal of Technology Transfer, 35(2), 181-202.

Muscio, A., \& Pozzali, A. (2013). The effects of cognitive distance in university-industry collaborations: Some evidence from Italien universities. Journal of Technology Transfer, 38(4), 486-508.

Nooteboom, B., Van Haverbeke, W., Duysters, G., Gilsing, V., \& Van den Oord, A. (2007). Optimal cognitive distance and absorptive capacity. Research Policy, 36(7), 1016-1034.

O'Kane, C., Mangematin, V., Geoghegan, W., \& Fitzgerald, C. (2015). University technology transfer offices: The search for identity to build legitimacy. Research Policy, 44(2), 421-437.

Okamuro, H., \& Nishimura, J. (2013). Impact of university intellectual property policy on the performance of university-industry research collaboration. Journal of Technology Transfer, 38(3), 273-301.

Ouchi, W. G. (1979). A conceptual framework for the design of organizational control mechanisms. Management Science, 25(9), 833-848.

Perkmann, M., Neely, A., \& Walsh, K. (2011). How should firms evaluate success in university-industry alliances? A performance measurement system. R\&D Management, 41(2), 202-216.

Perkmann, M., Tartari, V., McKelvey, M., Autio, E., Brostrom, A., D’Este, P., et al. (2013). Academic engagement and commercialisation: A review of the literature on university-industry relations. Research Policy, 42(2), 423-442.

Perkmann, M., \& Walsh, K. (2007). University-industry relationships and open innovation: Towards a research agenda. International Journal of Management Reviews, 9(4), 259-280.

Plewa, C., \& Quester, P. (2007). Key drivers of university-industry relationships: the role of organisational compatibility and personal experience. Journal of Services Marketing, 21(5), 370-382.

Qiu, S., Liu, X., \& Gao, T. (2017). Do emerging countries prefer local knowledge or distant knowledge? Spillover effect of university collaborations on local firms. Research Policy, 46(7), 1299-1311.

Rijsdijk, S. A., \& van den Ende, J. (2011). Control combinations in new product development projects. Journal of Product Innovation Management, 28(6), 868-880.

Rosenbloom, J. L., \& Ginther, D. K. (2017). Show me the money: Federal R\&D support for academic chemistry, 1990-2009. Research Policy, 46(8), 1454-1464.

Rothaermel, F. T., Agung, S. D., \& Jiang, L. (2007). University entrepreneurship: A taxonomy of the literature. Industrial and Corporate Change, 16(4), 691-791.

Rousseau, D. M. (2001). Schema, promise and mutuality: The building blocks of the psychological contract. Journal of Occupational and Organizational Psychology, 74(4), 511-541. 
Salomo, S., Weise, J., \& Gemünden, H. G. (2007). NPD planning activities and innovation performance: The mediating role of process management and the moderating effect of product innovativeness. Journal of Product Innovation Management, 24(4), 285-302.

Salter, A., Salandra, R., \& Walker, J. (2017). Exploring preferences for impact versus publications among UK business and management academics. Research Policy, 46(10), 1769-1782.

Sampson, R. C. (2007). R\&D alliances and firm performance: The impact of technological diversity and alliance organization on innovation. Academy of Management Journal, 50(2), 364-386.

Santoro, M. D., \& Bierly, P. E. (2006). Facilitators of knowledge transfer in university-industry collaborations: A knowledge-based perspective. IEEE Transactions on Engineering Management, 53(4), 495-507.

Santoro, M. D., \& Gopalakrishnan, S. (2001). Relationship dynamics between university research centers and industrial firms: Their impact on technology transfer activities. Journal of Technology Transfer, 26(1-2), 163-171.

Schartinger, D., Rammer, C., Fischer, M. M., \& Fröhlich, J. (2002). Knowledge interactions between universities and industry in Austria: Sectoral patterns and determinants. Research Policy, 31(3), 303-328.

Schleimer, S. C., \& Faems, D. (2016). Connecting interfirm and intrafirm collaboration in NPD projects: Does innovation context matter? Journal of Product Innovation Management, 33(2), 154-165.

Schultz, C., Salomo, S., de Brentani, U., \& Kleinschmidt, E. J. (2013a). How formal control influences decision-making clarity and innovation performance. Journal of Product Innovation Management, 30(3), 430-447.

Schultz, C., Salomo, S., \& Talke, K. (2013b). Measuring new product portfolio innovativeness: How differences in scale width and evaluator perspectives affect its relationship with performance. Journal of Product Innovation Management, 30(S1), 93-109.

Sethi, R., \& Iqbal, Z. (2008). Stage-Gate controls, learning failure, and adverse effect on novel new products. Journal of Marketing, 72(1), 118-134.

Sethi, R., Smith, D. C., \& Park, C. W. (2001). Cross-functional product development teams, creativity, and the innovativeness of new consumer products. Journal of Marketing Research, 38(1), 73-85.

Shaner, M. B., Beeler, L., \& Noble, C. H. (2016). Do we have to get along to innovate? The influence of multilevel social cohesion on new product and new service development. Journal of Product Innovation Management, 33(S1), 148-165.

Sherwood, A. L., \& Covin, J. G. (2008). Knowledge acquisition in university-industry alliances: An empirical investigation from a learning theory perspective. Journal of Product Innovation Management, 25(2), 162-179.

Siegel, D. S., Veugelers, R., \& Wright, M. (2007). Technology transfer offices and commercialization of university intellectual property: Performance and policy implications. Oxford Review of Economic Policy, 23(4), 640-660.

Song, M., Berends, H., van der Bij, H., \& Weggeman, M. (2007). The effect of IT and co-location on knowledge dissemination. Journal of Product Innovation Management, 24(1), 52-68.

Spanos, Y. E., Vonortas, N. S., \& Voudouris, I. (2015). Antecedents of innovation impacts in publicly funded collaborative R\&D projects. Technovation, 36-37, 53-64.

Spender, J. C. (1996). Making knowledge the basis of a dynamic theory of the firm. Strategic Management Journal, 17, 45-62.

Szymanski, D. M., Kroff, M. W., \& Troy, L. C. (2007). Innovativeness and new product success: Insights from the cumulative evidence. Journal of the Academy of Marketing Science, 35(1), 35-52.

Talke, K., Salomo, S., \& Rost, K. (2010). How top management team diversity affects innovativeness and performance via the strategic choice to focus on innovation fields. Research Policy, 39(7), 907-918.

Tartari, V., \& Breschi, S. (2012). Set them free: Scientists' evaluations of the benefits and costs of university-industry research collaboration. Industrial and Corporate Change, 21(5), 1117-1147.

Tessarolo, P. (2007). Is integration enough for fast product development? An empirical investigation of the contextual effects of product vision. Journal of Product Innovation Management, 24(1), 69-82.

Turner, K. L., \& Makhija, M. V. (2006). The role of organizational controls in managing knowledge. Academy of Management Review, 31(1), 197-217.

Verworn, B. (2009). A structural equation model of the impact of the "fuzzy front end" on the success of new product development. Research Policy, 38(10), 1571-1581.

Vlaar, P. W. L., Van den Bosch, F. A. J., \& Volberda, H. W. (2006). Coping with problems of understanding in interorganizational relationships: Using formalization as a means to make sense. Organization Studies, 27(11), 1617-1638.

Walter, S. G., Walter, A., \& Müller, D. (2015). Formalization, communication quality, and opportunistic behavior in R\&D alliances between competitors. Journal of Product Innovation Management, 32(6), 954-970. 
Weeth, A., Prigge, J.-K., \& Homburg, C. (2020). The role of departmental thought worlds in shaping escalation of commitment in new product development projects. Journal of Product Innovation Management, 37(1), 48-73.

Wirsich, A., Kock, A., Strumann, C., \& Schultz, C. (2016). Effects of university-industry collaboration on technological newness of firms. Journal of Product Innovation Management, 33(6), 708-725.

Yadav, M. S., Prabhu, J. C., \& Chandy, R. K. (2007). Managing the future: CEO attention and innovation outcomes. Journal of Marketing, 71(4), 84-101.

Zahra, S. A., \& George, G. (2002). Absorptive capacity: A review, reconceptualization, and extension. Academy of Management Review, 27(2), 185-203.

Publisher's Note Springer Nature remains neutral with regard to jurisdictional claims in published maps and institutional affiliations. 